\title{
Numerical Investigation on the Benefits of Preheating for an Increased Thermal Radius of Influence During Steam Injection in Saturated Soil
}

\author{
Kilian Weishaupt ${ }^{1}$ - Alexandre Bordenave ${ }^{2}$. \\ Olivier Atteia ${ }^{2}$. Holger Class ${ }^{1}$
}

Received: 13 May 2015 / Accepted: 5 January 2016 / Published online: 27 January 2016

(C) The Author(s) 2016. This article is published with open access at Springerlink.com

\begin{abstract}
The injection of steam is a well-established technique for the thermally enhanced remediation of both unsaturated and saturated soils. Under saturated conditions, there is a limitation related to the thermal radius of influence (TRI) which results from the balance between viscous forces due to injection and buoyant forces due to the density difference between steam and water. Targeted preheating of the soil reduces the required time for a gaseous (steam) flow to be established after the beginning of a steam injection into the soil. Compared to non-preheated zones, the region where steam exists reaches a larger lateral extent before buoyancy eventually leads to a vertical breakthrough of the steam. This study investigates the impacts of preheating on the thermal radius of influence by considering different preheating scenarios with a full-complexity, 3D, non-isothermal numerical model including phase change. The achievable benefits of preheating are discussed; the potential costs of preheating are also considered. It is shown that preheating increases the TRI by more than $10 \%$. This is not much, but it suggests that preheating is an interesting option in cases where the increased TRI leads to a reduced number of injection wells required.
\end{abstract}

Keywords Soil preheating $\cdot$ Thermal radius of influence $\cdot$ Steam injection $\cdot$ Saturated zone

\section{Introduction}

Steam injection for thermally enhanced soil remediation is an efficient and well-established technique which is often applied to remove NAPL (non-aqueous phase liquids) contamina-

Kilian Weishaupt

kilian.weishaupt@iws.uni-stuttgart.de

Holger Class

holger.class@iws.uni-stuttgart.de

1 Department of Hydromechanics and Modelling of Hydrosystems, Universität Stuttgart, Pfaffenwaldring 61, 70569 Stuttgart, Germany

2 ENSEGID, EA, 4592 Pessac, France 
tions both in the vadose zone and the saturated zone (Looney and Falta 2000; Ochs et al. 2010). Steam spreading behavior in unsaturated conditions is mainly governed by viscous forces exerted by the pressure gradient due to the injection. In saturated media, however, buoyancy effects that arise from the high-density difference between water and steam have a major impact on the steam zone development. As a result, the steam chamber spreads not only laterally but tends to migrate upwards where it eventually breaks through the groundwater table, thus limiting the effective range of an injection well (Gudbjerg et al. 2005; Ochs et al. 2010; Hiester et al. 2013). This range can be described by the so-called thermal radius of influence (TRI), a measure of the maximum radial distance from the well where steam saturation is greater than zero. Increasing the TRI or, in other words, the maximum horizontal extent of the steam zone would possibly reduce the required number of injection wells for a remediation project and therefore reduce the overall costs of the project.

One way of increasing the TRI is heating the soil prior to the actual steam injection. The hypothesis is that, in a preheated soil, less energy is required for steam formation during the injection process and the steam zone grows both faster and larger than in the case of steam injection without preheating. In addition, the direction the steam chamber spreads might be guided (e.g., toward the contamination) by selectively preheating a certain domain of the soil.

Producing steam from water of $10{ }^{\circ} \mathrm{C}$ requires approximately $2634 \mathrm{~kJ} / \mathrm{kg}$; this includes both the energy for heating the water to steam temperature $\left(100^{\circ} \mathrm{C}\right.$ at 1 bar $)$ and the latent heat of vaporization. In contrast, only about $2299 \mathrm{~kJ} / \mathrm{kg}$ is needed for steam generation from water of $90{ }^{\circ} \mathrm{C}$ since less energy is consumed to reach steam temperature. The ratio of those two specific enthalpies (1.15) is expected to be somehow proportional to the gain in TRI due to preheating $(+15 \%)$. Further effects might positively affect the TRI in a preheated soil. For instance, the reduction in viscosity due to an increase in temperature is expected to reduce the resistance for flowing water and steam.

Literature on influencing steam zone development is only sparse. Closmann (1968) developed an analytical approach to estimate the enhanced growth of the steam chamber in a preheated oil reservoir. However, in this case, the preheating is a result of the cyclic injection of steam after the first production cycle (Alvarez and Han 2013). This might, therefore, not be considered a dedicated preheating phase, especially since preheating by means of steam injection would again be compromised by unfavorable buoyancy effects. A patent (Glandt et al. 1990) exists for a method developed specifically for the production of tar sand deposits with oil viscosities and saturations too high for conventional steam injection procedures. There, a thin electrically conductive layer (e.g., water-saturated sand that locally intersperses the tar sand) is preheated using electrical current conducted by electrodes. This preheating reduces the viscosity up to a point where steam can be injected. The method explicitly creates a flow path for steam and guides it toward a desired location. For steam injection after preheating within an environmental context, however, apparently no literature data or practical experience is available. This holds both for the application of preheating itself and the prediction of possible preheating effects on steam propagation. This might be the result of the unclear benefits that preheating can achieve.

Therefore, this study aims at investigating the effects of soil preheating on the steam zone development in saturated media by means of numerical modeling.

The following section gives some fundamental background information on the relevant physical processes and dominating forces that determine the TRI. Then, the equations to model the processes, their numerical implementation and the treatment of problems with numerical robustness are explained. After that, five generic preheating scenarios as well as a realistic field-scale application are introduced and discussed. Finally, the results of the numerical study are discussed and summarized. 


\section{Fundamentals}

\subsection{Steam Zone Development in Saturated Media}

The spreading behavior of steam in saturated media is mainly dominated by the interaction of viscous and buoyant forces. Viscous forces originate from the fluid's resistance against flow induced by a pressure gradient due to its viscosity.

Since pressure is a scalar quantity, viscous forces do not act in a distinct spatial direction in homogeneous isotropic media, causing steam to spread radially from its source. In contrast, buoyant forces arise from the difference in density between water and steam and gravity only acts in vertical direction. Therefore, these forces have a distinct upward direction and lead to a vertically oriented steam zone development.

The ratio between these two forces determines the steam chamber shape and can be expressed by the dimensionless gravity number $G r$ (Van Lookeren 1983; Ochs et al. 2010):

$$
G r=\frac{\text { viscous forces }}{\text { buoyant forces }}=\left[\frac{\mu_{\mathrm{s}} Q_{\mathrm{s}}}{\pi\left(\rho_{0}-\rho_{\mathrm{s}}\right) g z_{\max }^{2}(t) K \rho_{\mathrm{s}}}\right]
$$

Here, $\mu_{\mathrm{s}}$ is the steam viscosity and $Q_{\mathrm{s}}$ the steam injection rate. The densities of water and steam are given by $\rho_{0}$ and $\rho_{\mathrm{s}}$, while $K$ describes the intrinsic permeability of the soil. The time-dependent maximum vertical extent of the steam zone is given by $z_{\max }(t)$. High injection rates in combination with low permeabilities lead to a strong influence of viscous forces and therefore to high $G r$ numbers.

Ochs et al. (2010) developed typecurves that describe the shape of the steam zone depending on the gravity number. The lower the $G r$, the more ovoid-shaped the steam zone due to the dominance of buoyant forces. In the early stages of steam zone development, the flux density within the zone is quite high due to the initially small size of the steam chamber. As it grows, the flux density decreases and buoyant forces become stronger. This means that the initially spherical shape of the steam zone becomes more and more ovoid with time.

\subsection{Numerical Modeling of Steam Propagation}

The development of non-isothermal compositional multi-phase models used for reservoir engineering reaches back to the 1970s (e.g., Coats et al. 1974; Coats 1976, 1980; Aziz and Settari 1979; Aziz et al. 1987). One decade later, growing interest in environmental issues (e.g., soil contamination) fostered the demand for numerical simulation tools, e.g., for the planning and design of remediation projects (Helmig 1997). Numerous robust and efficient models for the simulation of steam spreading in porous media are available for the unsaturated zone, e.g., (Falta et al. 1992a; Class et al. 2002). In recent years, numerical problems occurring when applying these models to saturated conditions have been reported (e.g., Forsyth 1993). This includes spurious pressure oscillations and spurious cold-water fluxes into the steam zone (Coats 1980; Falta et al. 1992b). Gudbjerg et al. (2004) showed that these spurious fluxes are induced by pressure oscillations that lead locally to an inversion of the pressure gradient, thereby pushing cold water into the steam zone and causing parts of the steam to condensate. This, in turn, leads to a decrease in gas-phase saturation and pressure, allowing even more cold water to intrude the steam zone. As a result, the model suffers from a bad convergence behavior or fails to converge at all. The authors could successfully tackle this issue by selectively blocking the fluxes of cold water into the steam zone.

Ochs et al. (2010) took up this mechanism for the development of a non-isothermal twophase one-component model ( $2 \mathrm{p} 1 \mathrm{cni})$, especially designed for simulating steam injection in 
Table 1 Primary variables and phase states for the $2 \mathrm{p} 1 \mathrm{cni}$ model

\begin{tabular}{lll}
\hline Phase state & Present phases & Primary variables \\
\hline 1 & Liquid water & $p_{\mathrm{g}}, T$ \\
2 & Gas (steam) & $p_{\mathrm{g}}, T$ \\
3 & Liquid water, gas (steam) & $p_{\mathrm{g}}(T), S_{\mathrm{W}}$ \\
\hline
\end{tabular}

saturated conditions. Here, water is considered as the only component in the system. This is justified by the small remaining amount of air in the saturated zone. The component water may exist in the liquid or gas (i.e., steam) phase. Evaporation and condensation allow a change of the state of aggregation between liquid and gaseous. According to the Gibbsian phase rule, this non-isothermal multiphase system requires two independent primary variables (Class et al. 2002). They are chosen depending on phase presence (see Table 1) and can be switched if a phase appears or vanishes. If there is only a single phase (steam or liquid water), the gas-phase pressure $p_{\mathrm{g}}$ and the temperature $T$ are selected as primary variables. If steam and liquid water are present, $T$ is no longer independent but a function of $p_{\mathrm{g}}$ because the boiling temperature of water increases with rising pressure. Now, $p_{\mathrm{g}}$ and the liquid water phase saturation $S_{\mathrm{W}}$ are chosen as primary variables.

The following mass balance equation is solved:

$$
\phi \frac{\partial \sum_{\alpha}\left(\rho_{\alpha} S_{\alpha}\right)}{\partial t}-\sum_{\alpha} \operatorname{div}\left\{\rho_{\alpha} \frac{k_{r \alpha}}{\mu_{\alpha}} \mathbf{K}\left(\operatorname{grad} p_{\alpha}-\rho_{\alpha} \mathbf{g}\right)\right\}-q^{w}=0
$$

Here, $\rho_{\alpha}, k_{r \alpha}, \mu_{\alpha}, p_{\alpha}$ and $S_{\alpha}$ are the density, relative mobility, viscosity, pressure and saturation of the phase $\alpha$. Both density and viscosity are dependent on temperature and pressure. The porosity of the solid matrix and its intrinsic permeability tensor are given by $\phi$ and $\mathbf{K}$. The gravitational acceleration is denoted by $\mathbf{g}$, and $q^{w}$ is a source or sink term for the component water.

The energy balance equation is given as:

$$
\begin{gathered}
\phi \frac{\partial \sum_{\alpha}\left(\rho_{\alpha} u_{\alpha} S_{\alpha}\right)}{\partial t}+(1-\phi) \frac{\partial \rho_{\mathrm{s}} c_{\mathrm{s}} T}{\partial t}-\operatorname{div}\left(\lambda_{\mathrm{pm}} \operatorname{grad} T\right) \\
-\sum_{\alpha} \operatorname{div}\left\{\rho_{\alpha} h_{\alpha} \frac{k_{r \alpha}}{\mu_{\alpha}} \mathbf{K}\left(\operatorname{grad} p_{\alpha}-\rho_{\alpha} \mathbf{g}\right)\right\}-q^{h}=0
\end{gathered}
$$

with $\rho_{\alpha}, u_{\alpha}$ and $S_{\alpha}$ denoting the density, internal energy and saturation of the phase $\alpha$. The porosity $\phi$, the solid density $\rho_{\mathrm{S}}$ and the solid heat capacity $c_{\mathrm{S}}$ describe the characteristics of the porous medium. $q^{h}$ is a source or sink of energy. Heat dispersion is neglected as it is assumed to play a minor role in this multiphase system.

The effective heat conductivity of the porous medium $\lambda_{\mathrm{pm}}$ (Somerton et al. 1974) calculates to:

$$
\lambda_{\mathrm{pm}}=\lambda_{s, \mathrm{dry}}+\sqrt{S_{\mathrm{w}}}\left(\lambda_{s, \text { wet }}-\lambda_{s, \mathrm{dry}}\right)
$$

Here, $\lambda_{s, \text { dry }}$ is the empirical bulk heat conductivity of dry soil and $\lambda_{s \text {, wet }}$ is the same parameter for a completely water-saturated soil.

If two phases are present, the gas-phase saturation $S_{\mathrm{g}}$ is calculated by:

$$
S_{\mathrm{g}}=1-S_{\mathrm{w}}
$$


The wetting phase pressure $p_{\mathrm{w}}$ is given by:

$$
p_{\mathrm{w}}=p_{\mathrm{g}}-p_{\mathrm{c}}
$$

where $p_{\mathrm{c}}$ is the macroscale capillary pressure which can be obtained by the well-known $p_{\mathrm{c}}-S_{\mathrm{W}}$-relation as given by van Genuchten (1980):

$$
\begin{aligned}
& p_{\mathrm{c}}=\frac{1}{\alpha_{v g}} \cdot\left(S_{e}^{\frac{-1}{m}}-1\right)^{\frac{1}{n}} \\
& S_{e}=\frac{S_{\mathrm{w}}-S_{\mathrm{wr}}}{1-S_{\mathrm{wr}}} \quad S_{\mathrm{wr}} \leq S_{\mathrm{w}} \leq 1
\end{aligned}
$$

Here, $m, n$ and $\alpha_{v g}$ are fitting parameters derived from experimental data. $S_{e}$ and $S_{\mathrm{wr}}$ describe the effective and residual water saturation, respectively.

For $k_{r \alpha}$, an extended approach of van Genuchten (1980) is used to account for the nonwetting phase relative permeability as well (Luckner et al. 1989):

$$
\begin{aligned}
k_{r, w} & =\sqrt{S_{e}}\left[1-\left(1-S_{e}^{\frac{1}{m}}\right)^{m}\right]^{2} \\
k_{r, n w} & =\left(1-S_{e}\right)^{\frac{1}{3}}\left[1-S_{e}^{\frac{1}{m}}\right]^{2 m}
\end{aligned}
$$

As described above,

$$
T=T\left(p_{\mathrm{g}}\right)
$$

is used to close the system if both phases are present. Here, tabulated values are used to derive the temperature from $p_{\mathrm{g}}$.

Ochs et al. (2010) implemented this model in MUFTE-UG (Assteerawatt et al. 2005) and successfully validated it with data gathered both from laboratory experiments and field-scale application observations. For this work, the same model including the mechanism for blocking spurious cold-water fluxes was implemented in $\mathrm{DuMu}^{\mathrm{x}}$ (Flemisch et al. 2011; Becker et al. 2015), a free and open-source simulator based on DUNE (Bastian et al. 2008a, b). The model was verified and validated using data provided by Ochs et al. (2010). During this process, the blocking mechanism proved to be highly advantageous in terms of simulation performance. For one given case, the number of time steps required for one simulation run decreased from 3282 to 158 when spurious fluxes were blocked. However, this benefit seems to be situation dependent and was not further investigated in this work. Further details related to this topic can be found in Gudbjerg et al. (2004). With the blocking mechanism enabled and using the model setups described in the following chapters, no convergence problems or oscillations could be observed.

All equations described above are discretized in space using the locally mass conservative box method (Huber and Helmig 2000). In short, the primal finite element mesh is overlaid with a secondary finite volume grid by constructing control volumes or "boxes" $B_{i}$ around the nodes $i$ where the values of the primary variables are stored (see Fig. 1). Each box is divided into subcontrol volumes $v_{i}^{k}$. Fluxes over the subcontrol volumes' edges $s_{f}$ are calculated at the integration point $x_{f}$ using the standard finite element approach with piecewise bilinear functions. Balance equations are then formulated for each box in an integral form. Applying the divergence theorem and using weighted residuals with piecewise constant weighting functions lead to the following expression for each box $B_{i}$ : 

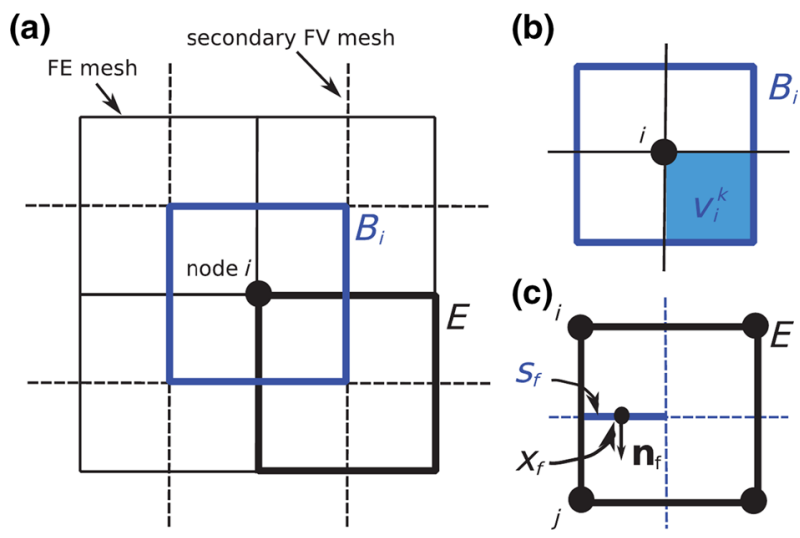

Fig. 1 Box scheme for the spatial discretization (Baber et al. 2012)

$$
\begin{aligned}
& \left|B_{i}\right| \frac{\hat{u}_{i}^{n+1}-\hat{u}_{i}^{n}}{\Delta t}+\sum_{f \in s(i)} \mathbf{F}_{\mathbf{A}}\left(\tilde{u}^{n+1}\left(x_{f}\right)\right) \cdot \mathbf{n}_{\mathbf{f}}\left|s_{f}\right| \\
& +\sum_{f \in s(i)} \mathbf{F}_{\mathbf{D}}\left(\tilde{u}^{n+1}\left(x_{f}\right)\right) \cdot \mathbf{n}_{\mathbf{f}}\left|s_{f}\right|-\left|B_{i}\right| q_{i}^{n+1}=0
\end{aligned}
$$

The volume of box $B_{i}$ is given by $\left|B_{i}\right|, \hat{u}_{i}$ is the solution of primary variable $u$ at node $i$ at time step $n$ and $n+1$. An outward pointing (relative to the box) unit normal vector $\mathbf{n}_{\mathbf{f}}$ is defined on each subcontrol volume face $f$ whose size is given by $\left|s_{f}\right|$. A source or sink is denoted $q_{i}^{n+1}$. Both advective $\mathbf{F}_{\mathbf{A}}$ and diffusive $\mathbf{F}_{\mathbf{D}}$ fluxes over the subcontrol volume faces $s(i)$ of box $B_{i}$ are computed at the integration points $x_{f}$, where $u$ is approximated by $\tilde{u}^{n+1}\left(x_{f}\right)=\sum_{k \in \eta_{E}} N_{k}\left(x_{f}\right) \hat{u}_{k}^{n+1}$. Here, $\eta_{E}$ are the nodes of element $E$.

The resulting system of nonlinear differential equations is then solved iteratively using the standard Newton-Raphson method (Helmig 1997):

$$
\underbrace{\left(\frac{\partial \mathbf{R}}{\partial \mathbf{u}}\right)_{n+1, m}}_{\mathbf{J}\left(\mathbf{u}^{\mathbf{n}+\mathbf{1}, \mathbf{m}}\right)} \underbrace{\left(\mathbf{u}^{n+1, m}-\mathbf{u}^{n+1, m-1}\right)}_{\Delta \mathbf{u}}=-\mathbf{R}\left(\mathbf{u}^{n+1, m}\right)
$$

where $\mathbf{u}$ is the vector of unknowns (i.e., the values of the primary variables). The Jacobian matrix $\mathbf{J}\left(\mathbf{u}^{\mathbf{n}+\mathbf{1}, \mathbf{m}}\right)$ is computed by numerical differentiation. The residuum at time step $n+1$ and iteration $m$ is given by $\mathbf{R}\left(\mathbf{u}^{n+1, m}\right)$, and $\Delta \mathbf{u}$ denotes the change of solution between two iterations. The iteration is continued until a chosen maximum relative tolerance of $\Delta \mathbf{u}$ is reached. For all calculations in this paper, a value of $1 \times 10^{-8}$ was set.

As the discretization in time is fully implicit, a heuristic time step control accounts for the convergence behavior of the Newton-Raphson scheme described in the following. The number in brackets indicates the values used for this paper. By comparing a set target number of Newton iterations $N_{\text {target }}(10)$ with the actual number of Newton iterations $N$, the new time step size $\Delta t^{n+1}$ is determined as follows:

$$
\Delta t^{n+1}=\left\{\begin{array}{lr}
\Delta t^{n}\left(\frac{1}{1+\left(N-N_{\text {target }}\right) / N_{\text {target }}}\right) & N_{\max }>N>N_{\text {target }} \\
\Delta t^{n}\left(1+\frac{N_{\text {target }}-N}{1.2 N_{\text {target }}}\right) & N \leq N_{\text {target }} \\
\Delta t^{n} 0.5 & N>N_{\max }
\end{array}\right.
$$


Here, $\Delta t^{n}$ is the previous time step size and $N_{\max }$ the number of Newton steps after which the time step size is halved (20).

\section{Numerical Investigations}

The basic impacts of soil preheating on steam propagation are demonstrated in the following by means of a simple generic model setup including a single injection well. A second setup employs a hypothetical field-scale application with two wells: one for steam injection and a second one for groundwater extraction. The section is then completed by a rough assessment of the economic aspects of preheating.

\subsection{Conceptual Study}

Setup: This model is a modified version of the one used by Ochs et al. (2010) for model validation. As steam is expected to spread radially symmetrically around the point of injection, only a segmental section of a cylinder with an opening angle of $1.0^{\circ}$, a radial extent of $5 \mathrm{~m}$ and a height of $7 \mathrm{~m}$ is modeled (Fig. 2). The grid cell size in $x$ - and $z$-direction is constant with $\mathrm{d} x=\mathrm{d} z=5 \mathrm{~cm}$. The soil parameters are given in Table 2. No-flow Neumann boundary conditions for energy and mass are assigned to the lateral boundaries for symmetrical reasons. The same applies for the front edge except for the segment between $2 \mathrm{~m} \leq z \leq 3 \mathrm{~m}$ where steam is injected. Here, an input rate for mass and energy is set as explained later. At the bottom, an impermeable layer is assumed, leading to the choice of a no-flow Neumann condition. To the top and back edge boundaries, Dirichlet values are assigned for temperature $\left(T=10.0^{\circ} \mathrm{C}\right)$ and pressure (hydrostatic conditions, $p_{\mathrm{g}}=1.013$ bar on top). The model only considers the saturated zone of the aquifer with an initial water saturation $S_{\mathrm{w}}=1.0$. The choice of a Dirichlet boundary condition for pressure at the top accounts for the eventual breakthrough of steam through the groundwater table. As the steam zone reaches the top, no accumulation or horizontal distribution of steam along the groundwater table takes place. Instead, steam leaves the saturated zone vertically and the pressure-driven steam zone growth in horizontal direction below the water table ceases.

The aim of these five scenarios (see Table 3) is to study the influence of preheating on steam propagation under different conditions. The variations considered are related to the steam

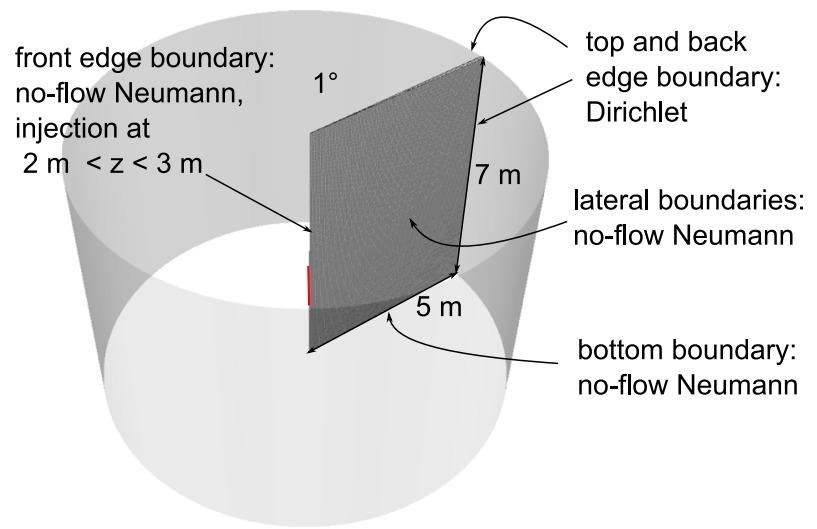

Fig. 2 Model setup for the conceptual study 
Table 2 Soil parameters for the segmental model

\begin{tabular}{llll}
\hline Soil parameter & Symbol & Value & Reference \\
\hline Porosity & $\phi$ & 0.4 & Ochs et al. (2003) \\
Soil grain density & $\rho_{\text {grain }}$ & $2650 \mathrm{~kg} / \mathrm{m}^{3}$ & Class et al. (2002) \\
Soil grain heat capacity & $\mathrm{c}$ & $\left.850 \mathrm{~J} / \mathrm{m}^{3} \mathrm{~K}\right)$ & Class et al. (2002) \\
Bulk heat conductivity dry soil & $\lambda_{s, \text { dry }}$ & $0.582(\mathrm{~m} \mathrm{~K})$ & Somerton et al. (1974) \\
Bulk heat conductivity wet soil & $\lambda_{s, \text { wet }}$ & $1.13(\mathrm{~m} \mathrm{~K})$ & Somerton et al. (1974) \\
Residual water saturation & $S_{\mathrm{Wr}}$ & 0.1 & Ochs et al. (2003) \\
Residual gas saturation & $S_{\text {gr }}$ & 0.0 & By definition \\
van Genuchten $\alpha$ & $\alpha_{v g}$ & $0.0028 \mathrm{~Pa}^{-1}$ & Ochs et al. (2003) \\
van Genuchten $n$ & $n_{v g}$ & 2.0 & Ochs et al. (2003) \\
\hline
\end{tabular}

Table 3 Model configuration for different scenarios of the

\begin{tabular}{lccc}
\hline Scenario & $Q_{\mathrm{S}}(\mathrm{kg} / \mathrm{h})$ & $\frac{K_{\mathrm{XX}}}{K_{\mathrm{ZZ}}}(-)$ & Injection depth $(\mathrm{m})$ \\
\hline 1 & 180 & 1 & 4.5 \\
2 & 180 & 1 & 14.5 \\
3 & 45 & 1 & 4.5 \\
4 & 45 & 3 & 4.5 \\
5 & 45 & 10 & 4.5 \\
\hline
\end{tabular}
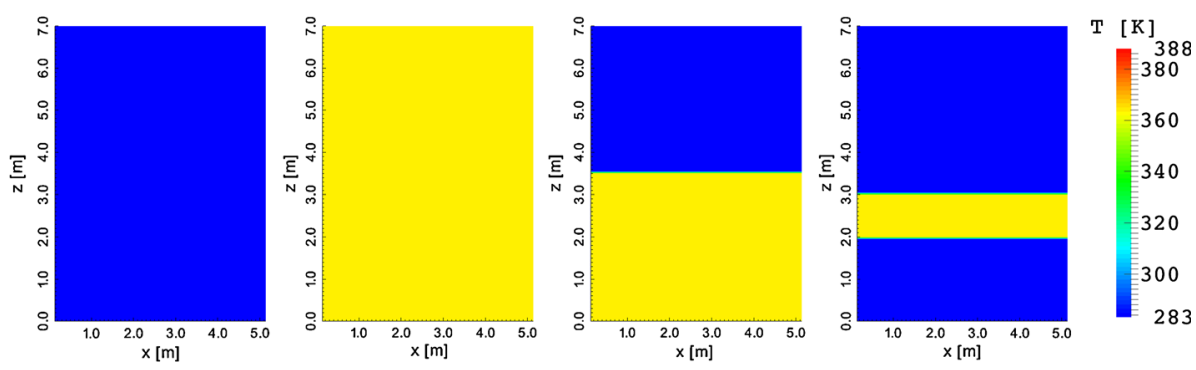

Fig. 3 Initial temperature distribution (degree of preheating from left to right none, all, half, stripe)

injection rate $Q_{\mathrm{s}}$, the injection depth and the anisotropy of permeability. A homogeneous horizontal intrinsic permeability of $K_{\mathrm{xx}}=K_{\mathrm{yy}}=1 \times 10^{-11} \mathrm{~m}^{2}$ is used for all scenarios, while the vertical permeability $K_{\mathrm{zz}}$ is varied as described below.

Scenarios 1 and 2 have the same steam injection rate and isotropic $\mathbf{K}$ with atmospheric gas-phase pressure of 1.013 bar on top of the domain. They differ in the depth at which the injection takes place. While the vertical center of the injection well is placed $4.5 \mathrm{~m}$ below the water table in Scenario 1, another $10 \mathrm{~m}$ is added to this height in Scenario 2. The remaining scenarios feature the same condition as Scenario 1, but with a lower steam injection rate. Their purpose is to investigate the impact of different anisotropy ratios $\frac{K_{\mathrm{xx}}}{K_{\mathrm{zz}}}$ for the horizontal and vertical permeability.

For each scenario, the same four different initial conditions for temperature represent various degrees of soil preheating. As can be seen in Fig. 3, the preheating cases are academic 

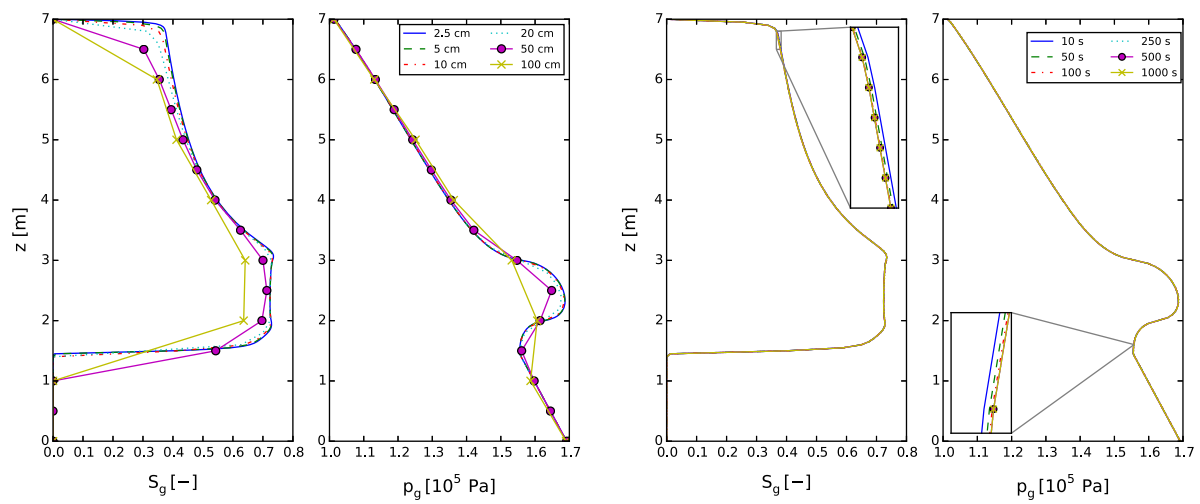

Fig. 4 Saturation and pressure distribution of the convergence study in space (left) and time (right)

rather than realistic, but they do show the range of results. In the first case, no preheating is applied, so the overall temperature equals $10^{\circ} \mathrm{C}$. In the second case, the whole domain has been preheated to $90^{\circ} \mathrm{C}$. The third case represents a scenario where the lower half of the domain is heated. The last case includes an area of preheated soil with a vertical extent of $1 \mathrm{~m}$, coinciding with the vertical position of the steam injection well.

Convergence study: Grid convergence is shown using the model setup from Scenario 1 described above (full preheating). The vertical distributions of gas-phase saturation $S_{\mathrm{g}}$ and gas-phase pressure $p_{\mathrm{g}}$ along the front edge of the domain are plotted on the left side in Fig. 4 for different mesh sizes $\mathrm{d} x=\mathrm{d} z$ ranging from 100 to $2.5 \mathrm{~cm}$. The maximum time step size for these simulations was fixed at $10 \mathrm{~s}$. The results indicate that the solutions converge to the one of the finest mesh size $(2.5 \mathrm{~cm})$ for both saturation and pressure.

To study convergence in time, a fixed mesh size of $\mathrm{d} x=\mathrm{d} z=2.5 \mathrm{~cm}$ and different maximum time step sizes $(10,50,100,250,5001000 \mathrm{~s})$ are chosen. As shown on the right side of Fig. 4, the results are virtually identical. For illustrative purposes, small sections of the curves have been magnified $\left(10 \times\right.$ for $S_{\mathrm{g}}, 400 \times$ for $\left.p_{\mathrm{g}}\right)$. This shows that the chosen maximum time step size does not have a great impact on the simulation outcome. Note that the actual time step size is chosen adaptively based on the convergence behavior of the Netwon-Raphson scheme.

Results: Figures 5, 6, 7, 8 and 9 show the vertical temperature distribution for all scenarios and all preheating cases after 6 and $24 \mathrm{~h}$. Further details are given in Table 4. For the sake of better comparability and to reduce negative impacts from the Dirichlet boundary conditions at the top of the domain, the time until steam breakthrough through the groundwater table $t_{\text {br }}$ is determined separately for each simulation run. All further calculations in Table 4 are derived from the quantities at this particular point in time. The steam chamber volume is given by $V_{\mathrm{s}}$. It was identified by considering all cells with a gas-phase saturation $S_{\mathrm{g}}$ greater than zero. The TRI describes the maximum radial extent of the steam zone. The percentage change of the values of interest due to the respective degree of preheating is given by $\Delta t_{\mathrm{br}}$, $\Delta V_{\mathrm{s}}$ and $\Delta \mathrm{TRI}$.

The temperature distribution after 6 and $24 \mathrm{~h}$ for the first scenario is shown in Fig. 5. In all preheating cases, the growth of the steam zone is enhanced in horizontal direction. As indicated in Table 4, the case with full preheating results in the greatest enlargement of TRI 

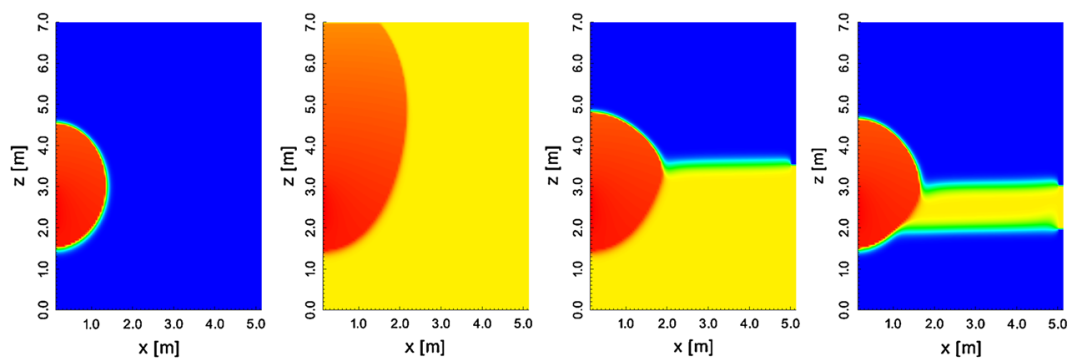

T $[\mathrm{K}]$ $=380$

360

340

320

300

283
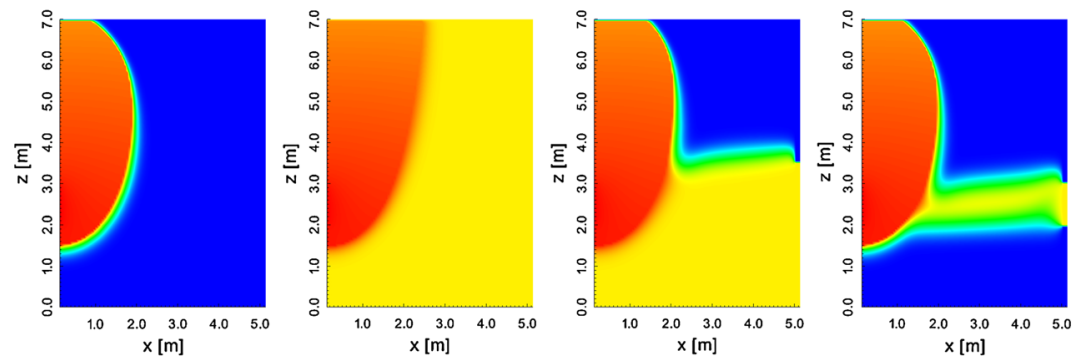

T [K]

388
$=380$

360

340

320

300

283

Fig. 5 Temperature distribution for Scenario 1 at $t=6 \mathrm{~h}$ (upper figures) and $t=24 \mathrm{~h}$ (lower figures)

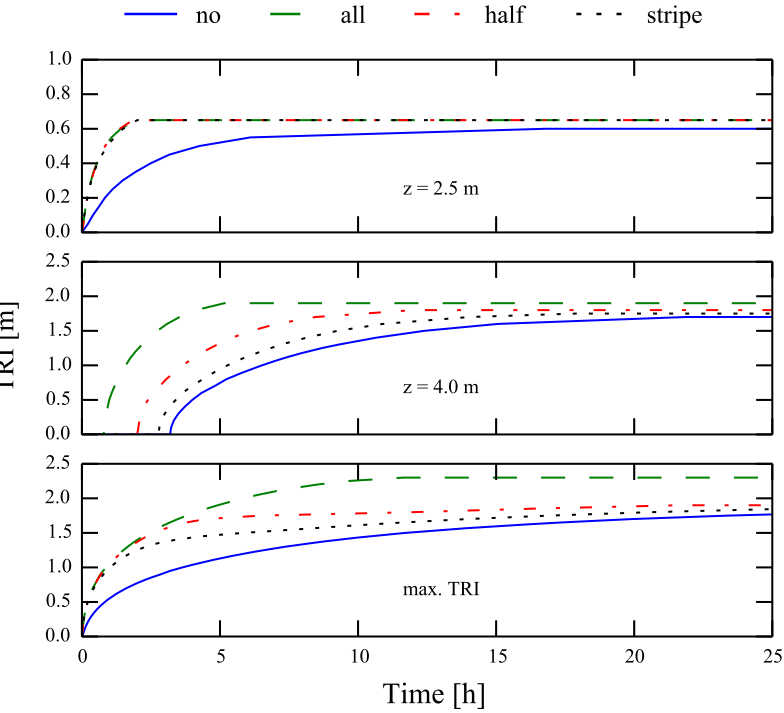

Fig. 6 TRI over time for Scenario 1 at different vertical locations

$(+12 \%)$ compared to the non-preheating case. However, the increase in TRI $(+9 \%)$ is not considerably lower after preheating only half of the domain or even a stripe. Though both of the latter two cases feature the same TRI, the resulting steam chamber volume for the stripe preheating case is lower because here the overall preheated area is smaller resulting in a slower steam propagation in the unheated areas. With full preheating, the time until steam breakthrough is reduced by a factor of about five, while the other two preheating cases do not seem to affect this quantity strongly. 

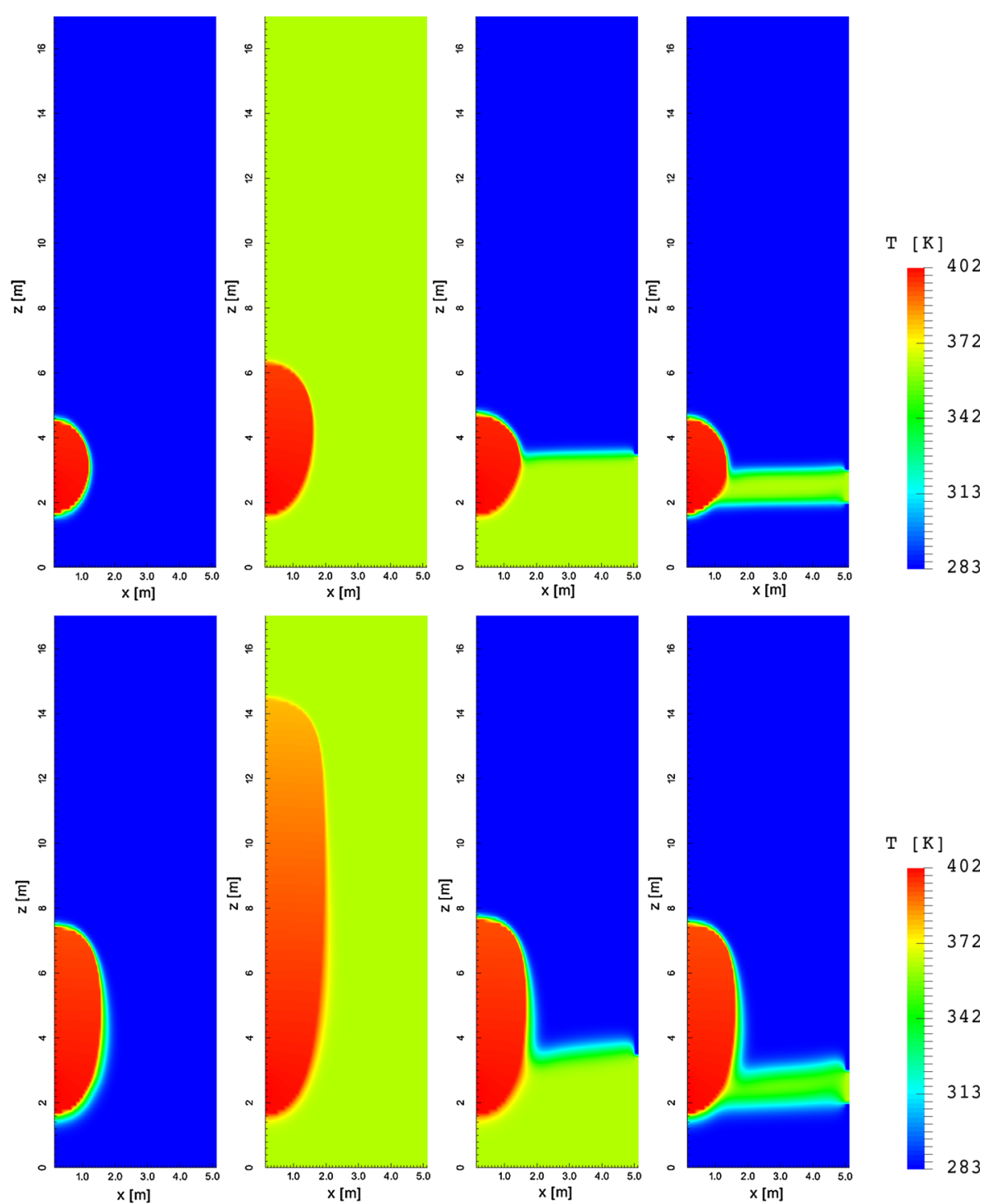

Fig. 7 Temperature distribution for Scenario 2 at $t=6 \mathrm{~h}$ (upper figures) and $t=24 \mathrm{~h}$ (lower figures)

The temporal development of the TRI for two fixed heights is shown in Fig. 6 together with the time series of the maximum TRI which occurs at varying vertical locations. The first plot location $(z=2.5 \mathrm{~m})$ represents the vertical center of the steam injection well. For all preheating cases, this point always lies within the preheated region. The results show clearly that the maximum TRI in the selected depth for all cases does not coincide with the global maximum which is due to the ovoid-shaped steam zone. The growth rate of the TRI is virtually identical for all preheating cases. The TRI increases fast at the beginning and reaches its maximum of $65 \mathrm{~cm}$ after about $2 \mathrm{~h}$. The non-preheating case reaches its maximum TRI of $60 \mathrm{~cm}$ only after $24 \mathrm{~h}$. The rate of growth itself decreases with time for both the preheated cases and the non-preheating one. 

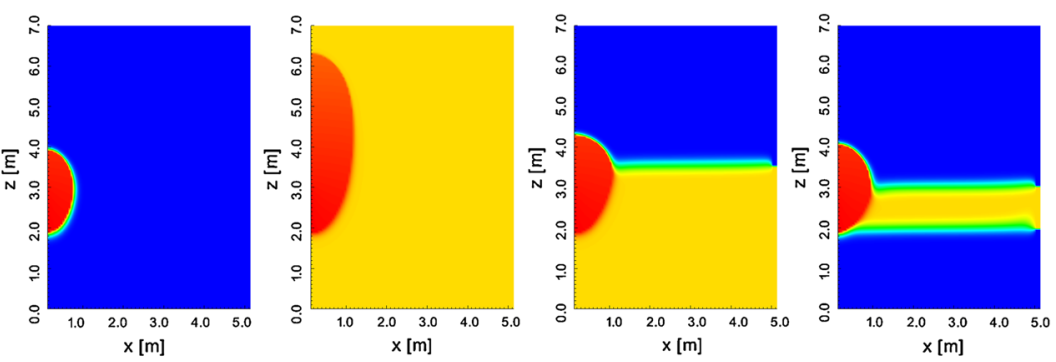

$\mathrm{T}[\mathrm{K}]$
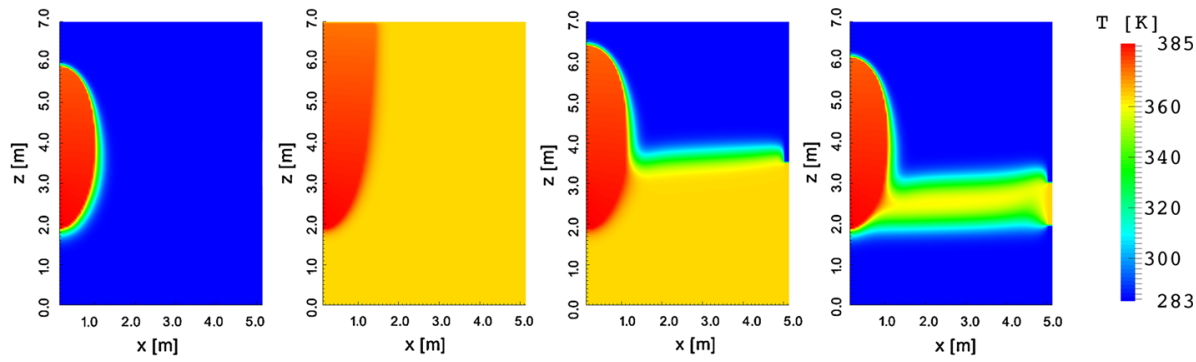

Fig. 8 Temperature distribution for Scenario 3 at $t=6 \mathrm{~h}$ (upper figures) and $t=24 \mathrm{~h}$ (lower figures)
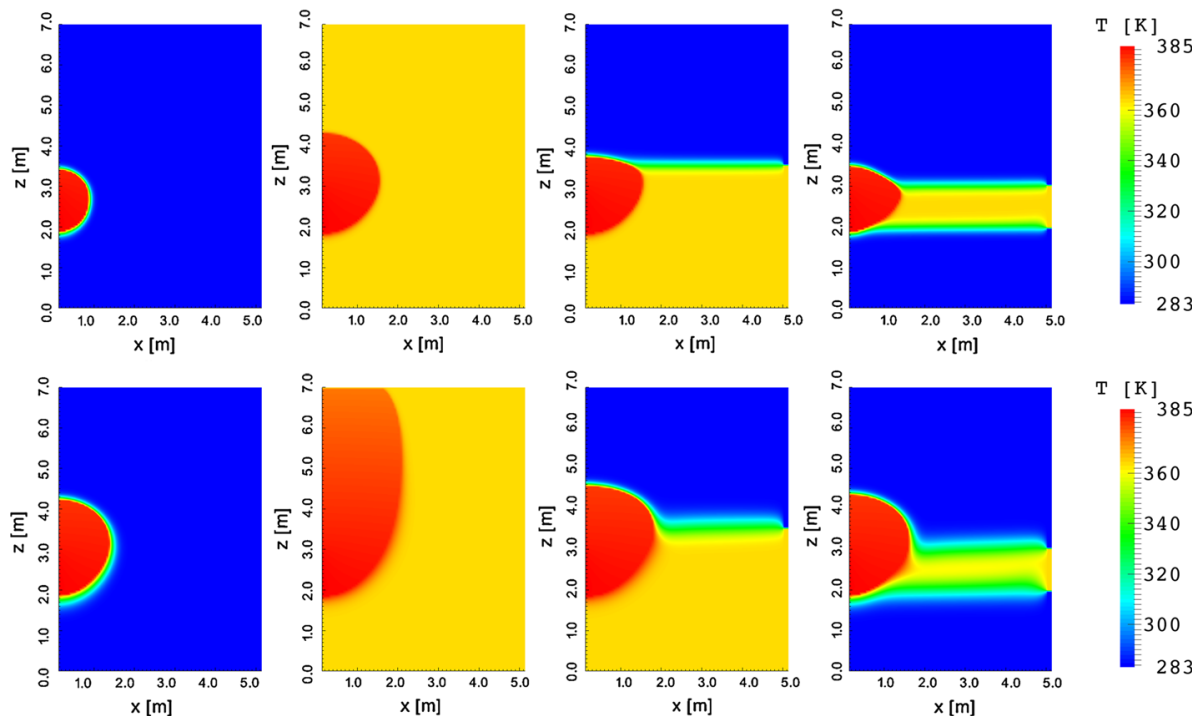

Fig. 9 Temperature distribution for Scenario 4 at $t=6 \mathrm{~h}$ (upper figures) and $t=24 \mathrm{~h}$ (lower figures)

The plot at $z=4 \mathrm{~m}$ lies above the preheated zone for the cases with half-domain and stripe preheating. The maximum TRI in $z=4 \mathrm{~m}$ is the highest for the case with full preheating. The more of the domain was preheated, the lower the time required to reach the maximum TRI.

The global maximum TRI occurs at different heights and at different times for the different cases. It is plotted in the lowermost graph. At early times, it is almost identical for all preheating cases. Its rate of growth declines with time as has been observed for the other depths. Note that the maximum TRI for the case with full preheating is higher than the value 
Table 4 Results for the conceptual preheating study

\begin{tabular}{|c|c|c|c|c|c|c|c|c|c|}
\hline Scenario & Preheating & $\begin{array}{l}Q_{\mathrm{s}} \\
(\mathrm{kg} / \mathrm{h})\end{array}$ & $\begin{array}{l}\frac{K_{\mathrm{XX}}}{K_{\mathrm{ZZ}}} \\
(-)\end{array}$ & $\begin{array}{l}t_{\mathrm{br}} \\
(\mathrm{h})\end{array}$ & $\begin{array}{l}V_{\mathrm{s}} \\
\left(\mathrm{m}^{3}\right)\end{array}$ & $\begin{array}{l}\text { TRI } \\
(\mathrm{m})\end{array}$ & $\begin{array}{l}\Delta t_{\mathrm{br}} \\
(\%)\end{array}$ & $\begin{array}{l}\Delta V_{\mathrm{s}} \\
(\%)\end{array}$ & $\begin{array}{l}\Delta \mathrm{TRI} \\
(\%)\end{array}$ \\
\hline \multirow[t]{4}{*}{1} & None & 180 & 1 & 22.2 & 39.31 & 1.70 & - & - & - \\
\hline & All & & & 4.9 & 46.40 & 1.90 & -88 & +18 & +12 \\
\hline & Half & & & 19.8 & 46.84 & 1.85 & -11 & +19 & +9 \\
\hline & Stripe & & & 21.2 & 42.73 & 1.85 & -5 & +9 & +9 \\
\hline \multirow[t]{4}{*}{$2^{\mathrm{a}}$} & None & 180 & 1 & 98.9 & 112.42 & 1.6 & - & - & - \\
\hline & All & & & 28.4 & 150.64 & 1.85 & -71 & +34 & +16 \\
\hline & Half & & & 94.9 & 127.05 & 1.7 & -4 & +13 & +6 \\
\hline & Stripe & & & 97.3 & 117.40 & 1.65 & -2 & +4 & +3 \\
\hline \multirow[t]{4}{*}{3} & None & 45 & 1 & 35.0 & 11.45 & 0.90 & - & - & - \\
\hline & All & & & 7.2 & 15.41 & 1.05 & -79 & +35 & +17 \\
\hline & Half & & & 29.0 & 13.86 & 0.95 & -17 & +21 & +6 \\
\hline & Stripe & & & 32.3 & 12.71 & 0.95 & -8 & +11 & +6 \\
\hline \multirow[t]{4}{*}{4} & None & 45 & 3 & 106.3 & 34.24 & 1.60 & - & - & - \\
\hline & All & & & 20.5 & 44.89 & 1.85 & -81 & +31 & +16 \\
\hline & Half & & & 88.3 & 42.95 & 1.80 & -17 & +25 & +13 \\
\hline & Stripe & & & 98.1 & 37.26 & 1.65 & -8 & +9 & +3 \\
\hline \multirow[t]{4}{*}{5} & None $^{b}$ & 45 & 10 & 480.0 & 119.41 & 3.00 & - & - & - \\
\hline & All & & & 67.3 & 146.02 & 3.45 & -86 & +22 & +15 \\
\hline & Half $^{b}$ & & & 480.0 & 136.04 & 3.40 & 0 & +14 & +13 \\
\hline & Stripe $^{b}$ & & & 480.0 & 130.61 & 3.20 & 0 & +9 & +7 \\
\hline
\end{tabular}

a Greater injection depth $(14.5 \mathrm{~m})$

b Steam front approached upper boundary up to a distance of less than $15 \mathrm{~cm}$ within the (maximum) simulation time of 20 days

$\frac{K_{\mathrm{XX}}}{K_{\mathrm{zz}}}$ : anisotropy ratio of hydraulic conductivity

$t_{\text {br }}$ : time until steam breakthrough

$V_{\mathrm{S}}$ : steam chamber volume (calculated for an entire radial domain)

TRI: maximum radial extent of the steam zone

$\Delta$ : percentage change of the quantity due to preheating

given in Table 4. As mentioned above, the values of the tables were taken at the time of steam breakthrough $\left(t_{\mathrm{br}}=4.9 \mathrm{~h}\right)$ in order to have comparable results with a low influence of the boundary condition at the top of the domain. Furthermore, it was not possible to define an explicit steady-state maximum TRI for all simulation runs.

In Scenario 2 (see Fig. 7), the injection of steam takes place under a higher hydrostatic pressure corresponding to the greater injection depth. As a result, the TRI for all preheating cases is smaller than in Scenario 1. Furthermore, the desired gain of TRI due to preheating is increased for the full preheating case, while it is decreased for the remaining cases.

The smaller steam injection rate in Scenario 3 results in an even more ovoid-shaped steam chamber. The model results also suggest that full preheating has a slightly stronger effect than in Scenario 1 ( +17 vs. $+12 \%)$, while the opposite is true for the remaining preheating cases. However, the increase in steam chamber volume due to preheating seems to be larger for a lower steam injection rate $(+18 \%$ in Scenario 1 vs. $+35 \%$ in Scenario 3 for the full preheating case). 

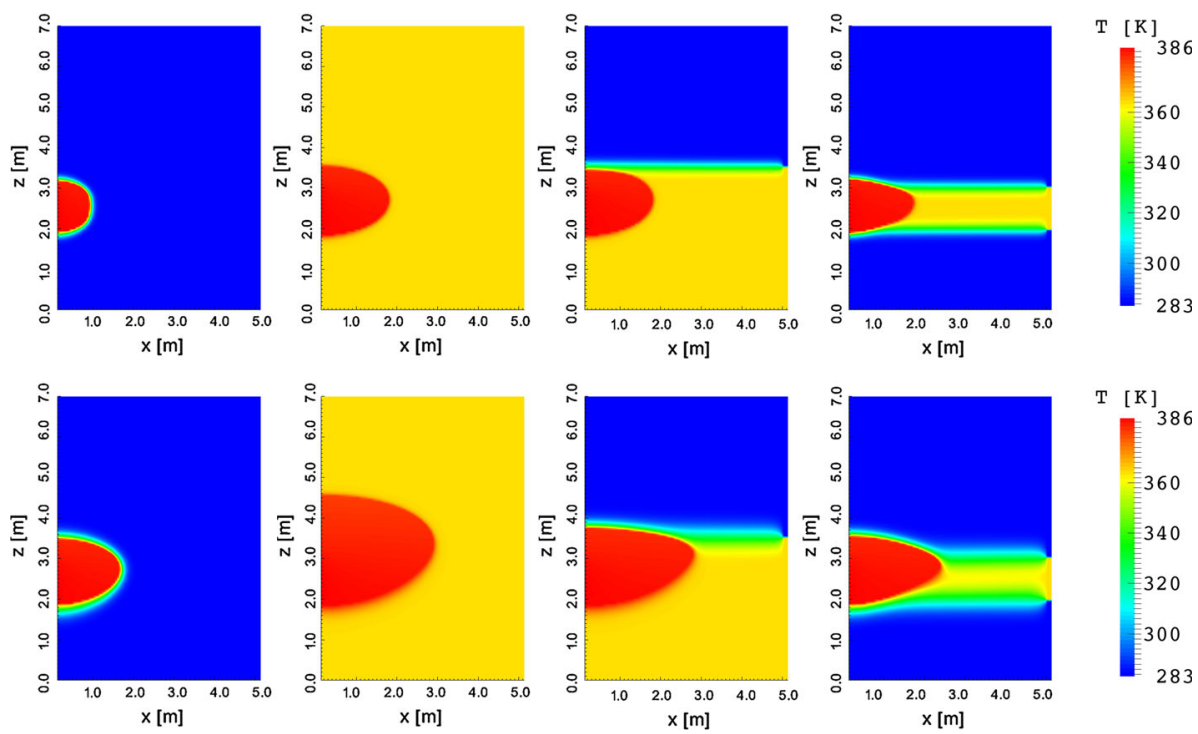

Fig. 10 Temperature distribution for Scenario 5 at $t=6 \mathrm{~h}$ (upper figures) and $t=24 \mathrm{~h}$ (lower figures)

Scenario 4 (Fig. 9) features an anisotropic hydraulic conductivity which results in more horizontal steam spreading. While the gain of TRI for the full preheating case does not differ much from the previous isotropic scenario $(+16 \%)$, the half preheating case appears to benefit strongly from the anisotropy $(+13 \%)$, an observation which does not hold for the stripe case $(+3 \%)$.

What is most striking in Scenario 5 (Fig. 10) is the long time it takes for the steam to break through the groundwater table. Except for the full preheating case, all other cases did not achieve this state within the given simulation time of 20 days. However, the distance between the upper domain boundary and the steam front was less than $15 \mathrm{~cm}$. Therefore, the results for the maximum TRI at steam breakthrough should not deviate much when it is kept in mind that the total height of the domain is $7 \mathrm{~m}$. The ratios for the TRI are in the range of the previous scenario.

\subsection{Field-Scale Application}

A hypothetical field-scale application case is used to investigate and discuss the effects for a more practically relevant scenario. Of particular interest here is the influence of an additional groundwater extraction well. In reality, it is often mandatory to ensure a so-called hydraulic safeguarding, which prevents the discharge of pollutants from the remediation zone during the cleanup process. For this reason, the extraction rate of water has to exceed the injection rate of steam or hot water. Furthermore, this study intends to illustrate (1) whether steam can be guided selectively toward a distinct direction, in this case toward the extraction well, and (2) how preheating affects this.

Setup: Fig. 11 shows the model setup. The size of the domain is quite large in order to minimize the effects of the boundary conditions. It has a spatial extent of $50 \times 30 \times 7 \mathrm{~m}^{3}$. In $x$ - and $y$-direction, the grid cell size is $2 \mathrm{~m}$, while in $z$-direction, it is $1 \mathrm{~m}$. 

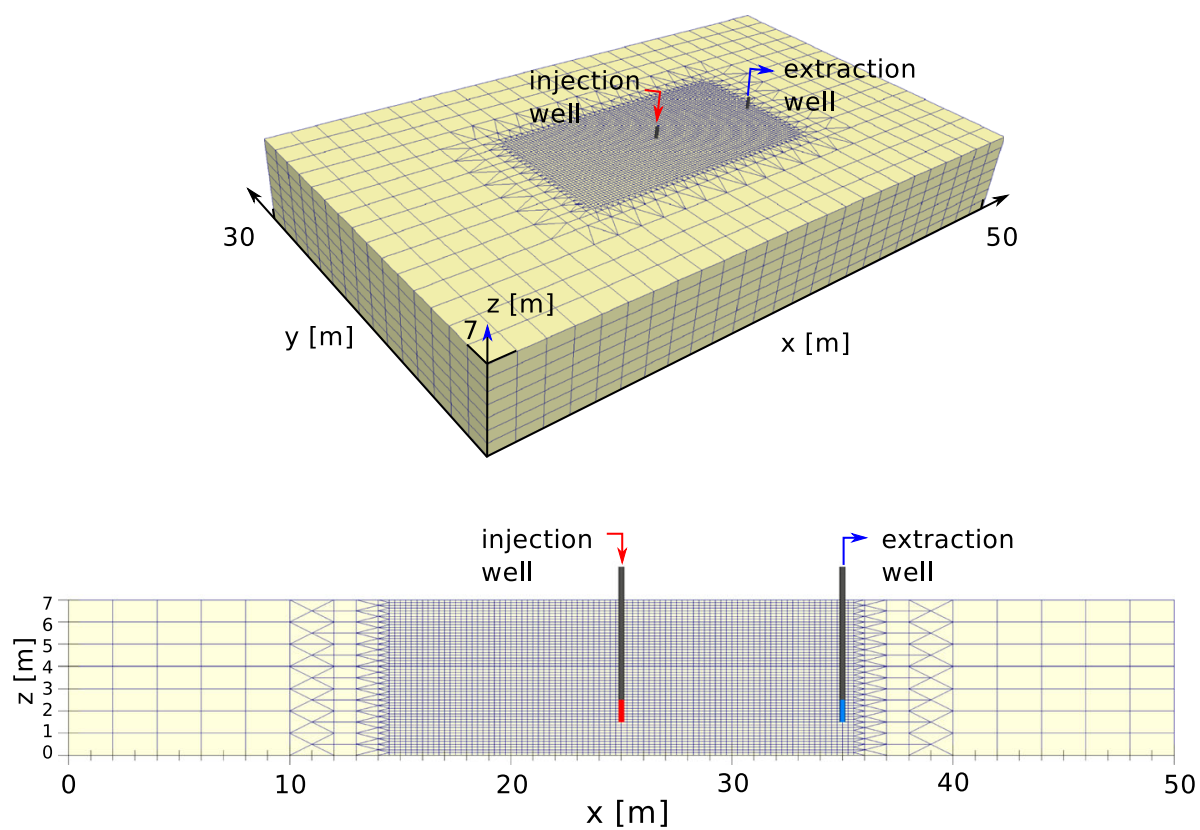

Fig. 11 Model setup for the field-scale application

A groundwater extraction well is situated at $x=35 \mathrm{~m}, y=15 \mathrm{~m}$. Hot water pre-injection and the steam injection itself take place at a well at $x=25 \mathrm{~m}, y=15 \mathrm{~m}$. Both wells are screened between $1.5 \mathrm{~m} \geq z \geq 2.5 \mathrm{~m}$. As the area of interest lies in the center of the domain, the grid is locally refined between $15 \mathrm{~m}<x<35 \mathrm{~m}$ and $10 \mathrm{~m}<y<20 \mathrm{~m}$, yielding $\mathrm{d} x=\mathrm{d} y=0.25 \mathrm{~m}$ and $\mathrm{d} z=0.125 \mathrm{~m}$.

On the assumption of an impermeable layer at the bottom, a no-flow Neumann condition for mass flux and a Dirichlet boundary condition for temperature $\left(T=10^{\circ} \mathrm{C}\right)$ are applied.

Dirichlet boundary conditions for temperature $\left(T=10^{\circ} \mathrm{C}\right)$ and pressure (hydrostatic pressure, atmospheric conditions) are assigned to the lateral sides and to the top of the domain. This corresponds to a static, undisturbed basic state of the unconfined aquifer. Note that the $2 \mathrm{p} 1 \mathrm{cni}$ model (see 2.2) does not yet consider changes in water table height due to extraction or injection. The use of a Dirichlet boundary condition for pressure at the top is a trade-off and explained in the previous section. Using a coupling approach with, for example, the Richards model already available in $\mathrm{DuMu}^{\mathrm{x}}$ might be an interesting option for further studies.

Concerning soil parameters, the same values as in the previous simulations are used (see 2). The choice of $K_{\mathrm{xx}}=1 \times 10^{-11} \mathrm{~m}^{2}$ and $K_{\mathrm{zz}}=1 \times 10^{-12} \mathrm{~m}^{2}$ yields an anisotropy factor for the hydraulic conductivity of 10 which is a commonly observed value for sedimentary layers. The steam injection rate is $Q_{\mathrm{s}}=180 \mathrm{~kg} / \mathrm{h}$.

Four scenarios (see Table 5) are simulated. First (A1), only steam is injected without any preheating or groundwater extraction. In the second scenario (A2), hot water of $T=90^{\circ} \mathrm{C}$ is injected for $48 \mathrm{~h}$ prior to steam injection at the same well, but still no water is extracted. In Scenario B1, the extraction well is switched on and produces water at a rate of $1.5 \mathrm{~kg} / \mathrm{s}$. The last scenario (B2) includes both preheating and groundwater extraction. 
Table 5 Model configuration for the different scenarios of the hypothetical field-scale application

\begin{tabular}{llllllll}
\hline Scenario & Preheating & Extraction well & $\begin{array}{l}Q_{\mathrm{s}} \\
(\mathrm{kg} / \mathrm{h})\end{array}$ & $\begin{array}{c}\frac{K_{\mathrm{Xx}}}{K_{\mathrm{zz}}} \\
(-)\end{array}$ & $\begin{array}{c}Q_{\mathrm{pre}} \\
(\mathrm{kg} / \mathrm{s})\end{array}$ & $\begin{array}{l}t_{\mathrm{pre}} \\
(\mathrm{h})\end{array}$ & $\begin{array}{c}Q_{\text {ex }} \\
(\mathrm{kg} / \mathrm{s})\end{array}$ \\
\hline A1 & No & No & 180 & 10 & - & - & - \\
$\mathrm{A} 2$ & Yes & No & & & 1 & 48 & - \\
B1 & No & Yes & & & - & - & 1.5 \\
B2 & Yes & Yes & & & 1 & 48 & 1.5 \\
\hline
\end{tabular}

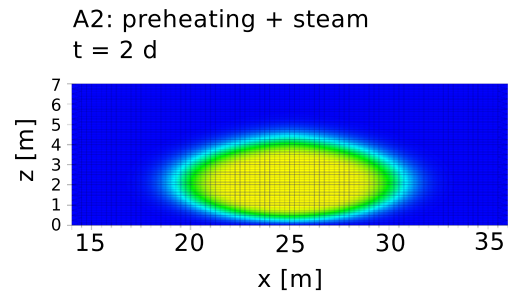

B2: preheating + steam + extraction $\mathrm{t}=2 \mathrm{~d}$

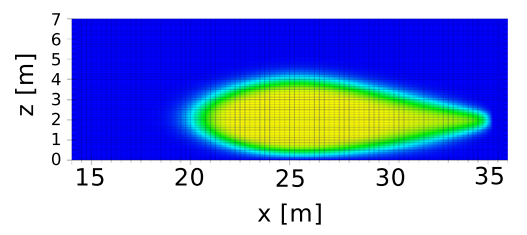

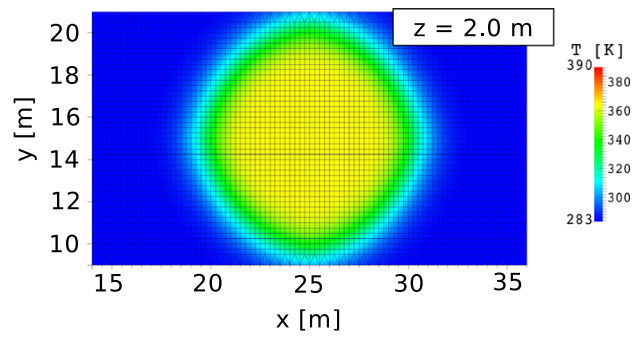

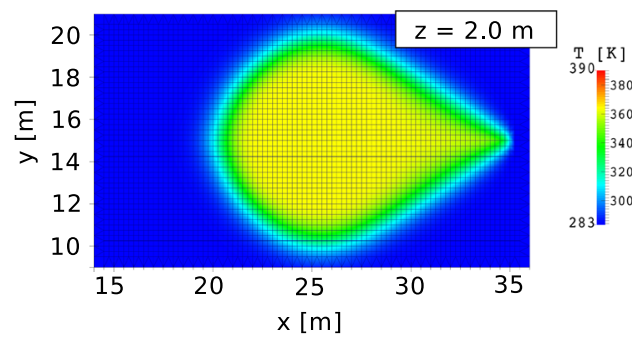

Fig. 12 Vertical (left) and horizontal (right, $z=2 \mathrm{~m}$ ) temperature distribution for Scenario A2 (upper figures) and B2 (lower figures) directly after the preheating phase

Results: Figure 12 depicts the temperature distribution for Scenarios A2 and B2 directly after the preheating phase has stopped. The figures are close-ups of the refined zone within the center of the model domain. The vertical cuts (left-hand side) are made at $y=15 \mathrm{~m}$, while the horizontal cuts (right-hand side) are made at the height where the preheated zone has its maximum horizontal extent $(z=2 \mathrm{~m})$.

Without any groundwater flow, preheating for $48 \mathrm{~h}$ leads to a circular-shaped area of increased temperature with a radius of about $7 \mathrm{~m}$. The influence of the extraction well (lower figures) is clearly visible as it attracts hot water toward itself.

Figures 13 and 14 show the temperature distributions for all scenarios after 5 and 10 days.

Table 6 summarizes the results. Both the TRI and the steam chamber volume $V_{\mathrm{s}}$ are given after 5 and 10 days as well as the percentage change due to preheating $\Delta V_{\mathrm{s}}$ and $\Delta$ TRI. Here, the TRI describes the maximum horizontal extent of the steam zone.

After 5 days, which corresponds to three days of steam injection, the effect of preheating can be observed for both cases, with and without extraction well.

With preheating, the TRI for Scenario A2 increased by $+31 \%$, the respective steam chamber volume by as much as $+111 \%$. For the case with extraction well (B2), the benefit of preheating is lower but still quite noticeable. The TRI is increased by $+18 \%$, while $V_{\mathrm{s}}$ grows by $+72 \%$. 

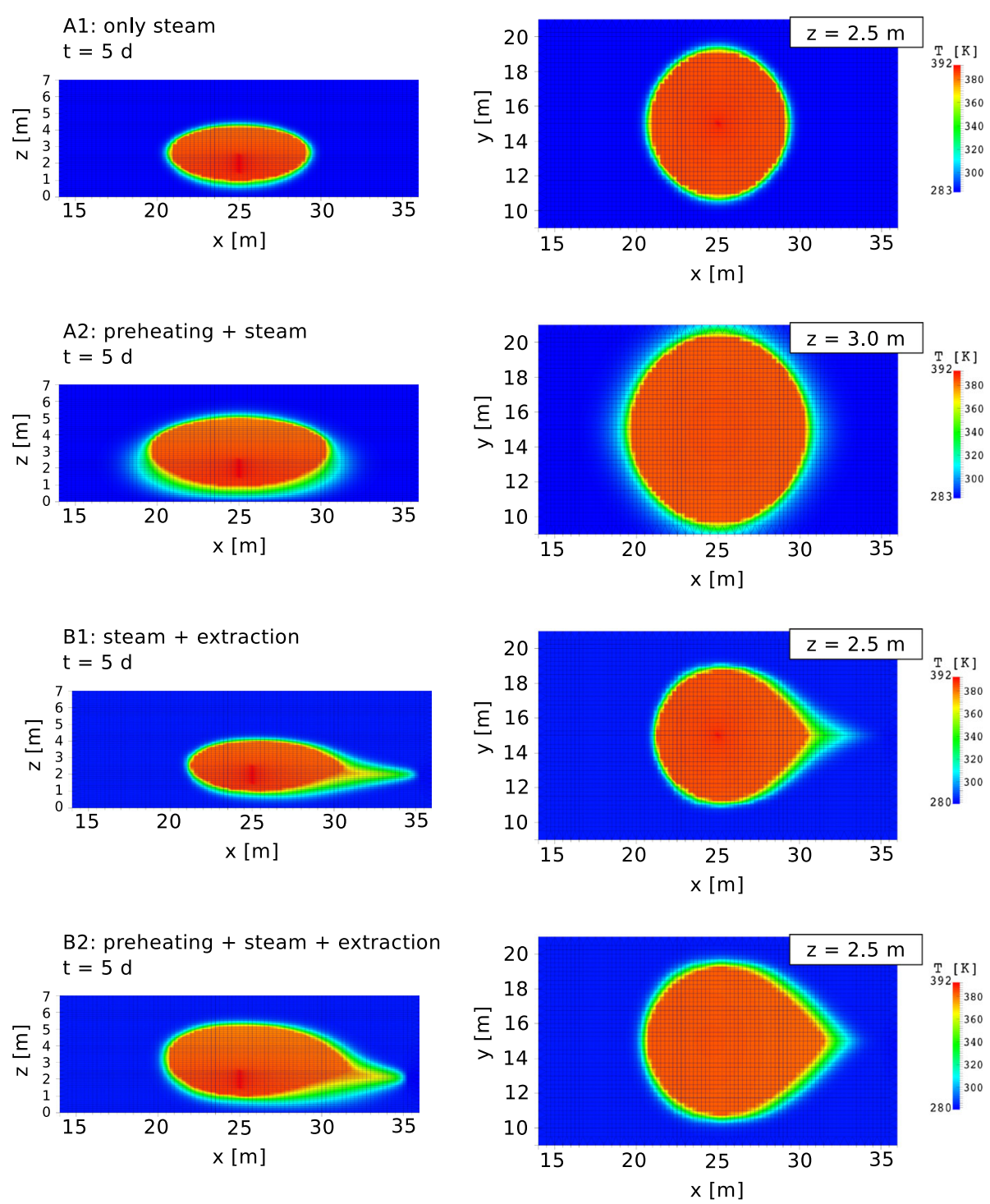

Fig. 13 Vertical (left) and horizontal (right) temperature distribution for all scenarios after $t=5$ days

Another five days later, the increase in TRI and $V_{\mathrm{s}}$ due to preheating is still noticeable, but lower than before. This corresponds to the observations made before in the conceptual study: Preheating yields the highest benefit at early stages of steam injection, and as time advances, the horizontal growth rate declines. The relative gain of TRI after 10 days for Scenario A2 is $+10 \%$, and for $\mathrm{B} 2$ the value is $+8 \%$.

Again, this is in agreement with observations in the conceptual study (above) where TRI benefits between +3 and $+17 \%$ could be found in the long term (see Table 4 ). 

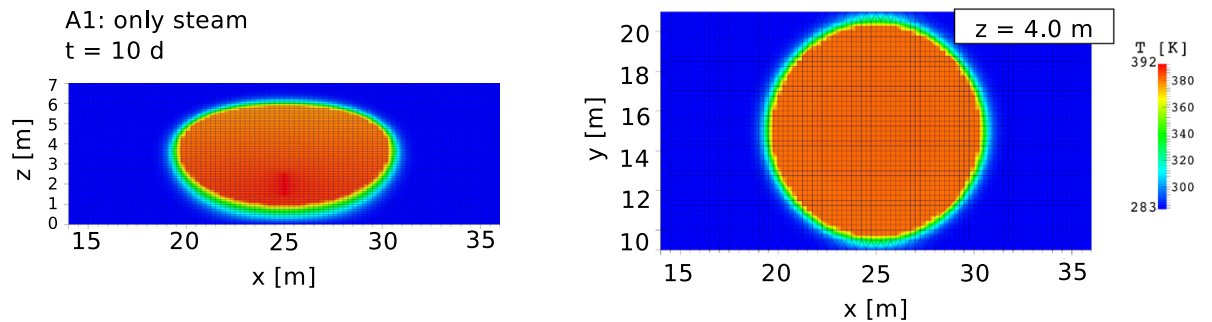

A2: preheating + steam $\mathrm{t}=10 \mathrm{~d}$
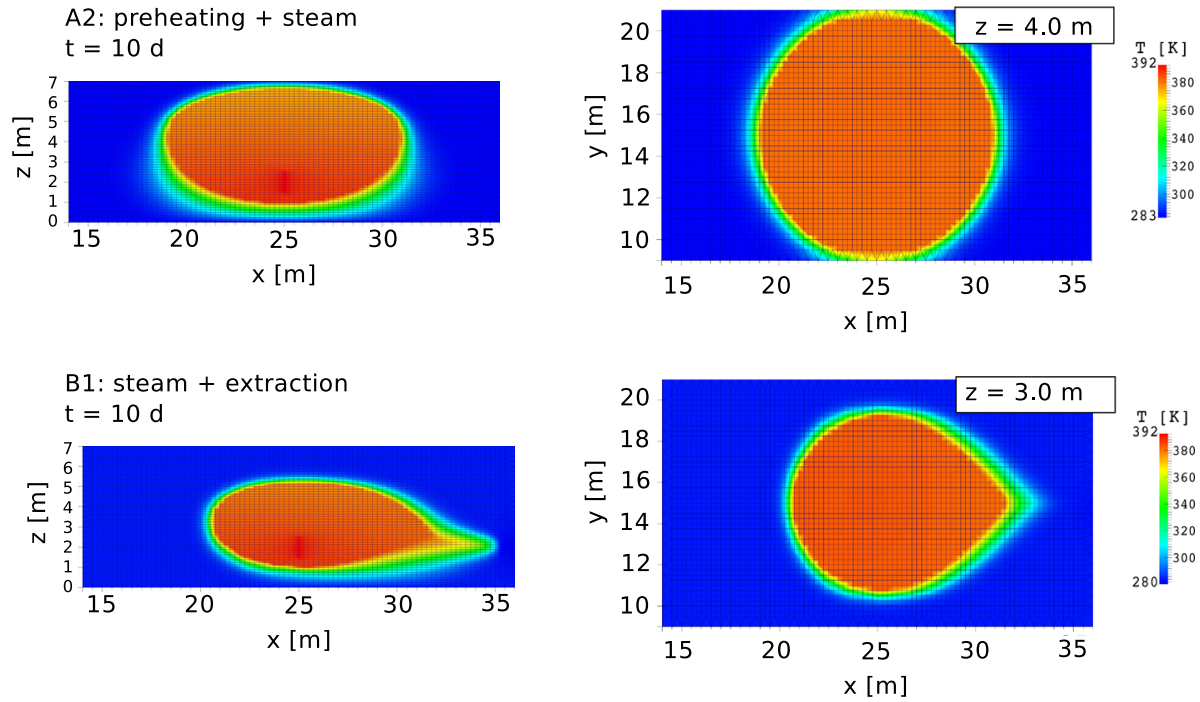

B2: preheating + steam + extraction $\mathrm{t}=10 \mathrm{~d}$
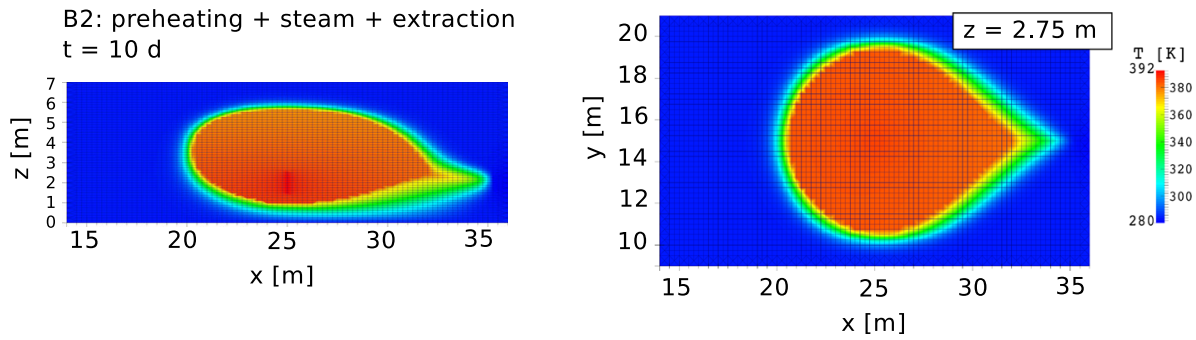

Fig. 14 Vertical (left) and horizontal (right) temperature distribution for all scenarios after $t=10$ days

Table 6 Results of the field-scale application

\begin{tabular}{|c|c|c|c|c|c|c|c|c|}
\hline \multirow[t]{2}{*}{ Scenario } & \multicolumn{2}{|c|}{ TRI [m] } & \multicolumn{2}{|l|}{$V_{\mathrm{s}}\left[\mathrm{m}^{3}\right]$} & \multicolumn{2}{|c|}{$\Delta \mathrm{TRI}(\%)$} & \multicolumn{2}{|c|}{$\Delta V_{\mathrm{s}}(\%)$} \\
\hline & 5 days & 10 days & 5 days & 10 days & 5 days & 10 days & 5 days & 10 days \\
\hline A1 & 4.00 & 5.25 & 102.94 & 276.91 & - & - & - & - \\
\hline $\mathrm{A} 2$ & 5.25 & 5.75 & 217.69 & 397.14 & +31 & +10 & +111 & +43 \\
\hline B1 & 5.50 & 6.50 & 85.30 & 169.95 & - & - & - & - \\
\hline B2 & 6.50 & 7.00 & 146.70 & 225.89 & +18 & +8 & +72 & +33 \\
\hline
\end{tabular}

The percentage change is given for the respective cases without preheating (A1 and B1) 


\section{Discussion and Conclusions}

The conceptual study reveals the basic characteristics of steam spreading in a preheated soil and how this behavior is sensitive to the various model parameters. The growth rate of the steam zone diminishes with time as it is clearly visible in Scenario 1 (see Fig. 6). This is due to the changing ratio between viscous and buoyant forces. Buoyancy increasingly predominates as the steam zone grows and flux densities become smaller.

A comparison of Scenarios 1 and 2 shows that the increase in injection depth in Scenario 2 leads to a more ovoid-shaped steam zone (see Fig. 7) with a decreased TRI. This can be explained by the fact that the model uses a prescribed value for mass and enthalpy input: Due to the higher pressure, the steam saturation temperature is increased which means that more enthalpy is required to heat the water to this point. Furthermore, the increase in steam density leads to a reduction in steam injection volume which, in turn, reduces the pressure gradient and the viscous forces that would be responsible for the radial steam spreading. While steam density is increased by the higher pressure, water density remains virtually constant due to its very low compressibility. The decreased density difference between water and steam should result in lower buoyancy effects and more radial spreading. However, this is more than compensated for by the first two effects as explained above.

In Scenario 3, where the steam injection rate $Q_{\mathrm{s}}$ is reduced, similar effects occur due to the decrease in viscous forces. Both Scenarios 2 and 3 feature a comparatively low gravitational number $G r$ and thus conditions that are rather unfavorable for steam injection. Preheating increases the TRI noticeably in these circumstances.

The permeability anisotropy in Scenarios 4 and 5 results in the expected intensified horizontal steam spreading and an increase in TRI even without preheating; this can, of course, be further enlarged by preheating.

In summary, the results of the conceptual study show that the TRI is always larger in a preheated soil. The greater the preheated zone, the stronger the increase in the TRI. Although it is not feasible in reality to heat the entire domain of interest, this study still shows what preheating can achieve under optimal (hypothetical) conditions. The increase of +12 to $+17 \%$ lies in the range of what was expected based on the results of first rough calculations regarding enthalpy. Variations in steam injection rate, depth and anisotropy have an impact on this result, but not a very significant one.

Preheating increases the TRI in more realistic scenarios with groundwater background flow as well, achieved in the example presented above with a pumping well. With this flow, the TRI is already enlarged even without preheating. Consequently, pre-injecting hot water does not yield quite the same gain of effective range as the cases without groundwater background flow. Nevertheless, $+8 \%$ of additional TRI can still be reached by preheating. With reference to Table 6 , the comparison between the scenarios with and without preheating leads to the conclusion that, in case of a cyclic injection scenario, all but the first injection episodes benefit from reaching a certain TRI in less time than in cold soil.

A rough monetary assessment of the hypothetical field-scale application was performed. For a well, costs of $€ 500$ per meter borehole depth were estimated based on expert knowledge, including the expenses for both material and construction works. Fuel costs were priced at $3.76 \mathrm{cent} / \mathrm{kWh}$ for gas (German Federal Ministry for Economic Affairs and Energy 2014), and a total efficiency of energy conversion of $85 \%$ was assumed (Ganapathy 1994). On the basis of the expenses for the wells, the energy required for preheating and the energy used for steam generation over ten days, a total cost for each injection scenario was calculated. This value was then divided by the respective maximum TRI in order to get relative, comparable results. 
For the scenarios without groundwater extraction, $€ 737$ per meter TRI without preheating (A1) and $€ 797$ per meter TRI with preheating (A2) were estimated. For the scenarios with extraction well, the respective values were $€ 1018$ (B1) and $€ 1047$ (B2) per meter TRI. Note that the costs relating to an area of thermal influence change quadratically and are hence more sensitive to an increase in TRI.

The assessment indicates that preheating is economically questionable for these cases, although this does not mean it should be rejected out of hand. Different economic circumstances could lead to more favorable conclusions with respect to preheating. Preheating by means of hot water pre-injection does not require many investments from a technical point of view. No additional well has to be drilled. The steam injection well already available can also be used for hot water injection. Some additional costs may occur due to the need for pumps and other technical equipment that can withstand the increased temperature of the hot water used for preheating. However, the main expenses arise from the provision of energy for heating the water. Addressing this issue could increase the profitability of preheating most profoundly. During summertime, for example, mobile solar collectors could provide energy at a significantly lower cost. The reduction in $\mathrm{CO}_{2}$ emissions associated with the use of renewable energy could further increase the environmental acceptability of the method. In addition, it might be viable for greater borehole depths which drastically increase the total costs per well, and the estimated $€ 500$ per meter borehole depth does not hold anymore. This also applies if the price of steel or other construction material increases further which appears to be a realistic prospect.

It can be concluded that preheating the soil prior to an injection of steam into the saturated zone for the purpose of increasing the thermal radius of influence is an interesting option that has clear physical limits, but should be considered for each individual case as it might offer an opportunity to reduce the overall costs of a project. The deeper the zone where the steam injection takes place, the more important an extended TRI by preheating is, since the costs for an additional well increase.

Acknowledgments The financial support in the form of the Student Thesis Scholarship granted by the International Training Group Non-Linearities and Upscaling in Porous Media (NUPUS), Deutsche Forschungsgemeinschaft GRK1398, is gratefully acknowledged.

Open Access This article is distributed under the terms of the Creative Commons Attribution 4.0 International License (http://creativecommons.org/licenses/by/4.0/), which permits unrestricted use, distribution, and reproduction in any medium, provided you give appropriate credit to the original author(s) and the source, provide a link to the Creative Commons license, and indicate if changes were made.

\section{References}

Alvarez, J., Han, S.: Current overview of cyclic steam injection process. J. Petrol. Sci. Res. 2(3), 116 (2013) Assteerawatt, A., Bastian, P., Bielinski, A., Breiting, T., Class, H., Ebigbo, A., Eichel, H., Freiboth, S., Helmig, R., Kopp, A., et al.: MUFTE-UG: structure, applications and numerical methods. Newsletter, International Groundwater Modeling Centre, Colorado School of Mines 23(2), 10 (2005)

Aziz, K., Settari, A.: Petroleum Reservoir Simulation. Applied Science Publ. Ltd., London (1979)

Aziz, K., Ramesh, A., Woo, P., et al.: Fourth spe comparative solution project: comparison of steam injection simulators. J. Petrol. Technol. 39(12), 1-576 (1987)

Baber, K., Mosthaf, K., Flemisch, B., Helmig, R., Müthing, S., Wohlmuth, B.: Numerical scheme for coupling two-phase compositional porous-media flow and one-phase compositional free flow. IMA J. Appl. Math. (Institute of Mathematics and Its Applications) 77(6), 887-909 (2012) 
Bastian, P., Blatt, M., Dedner, A., Engwer, C., Klöfkorn, R., Kornhuber, R., Ohlberger, M., Sander, O.: A generic grid interface for parallel and adaptive scientific computing. Part I: abstract framework. Computing 82(23), 103-119 (2008a)

Bastian, P., Blatt, M., Dedner, A., Engwer, C., Klöfkorn, R., Kornhuber, R., Ohlberger, M., Sander, O.: A generic grid interface for parallel and adaptive scientific computing. Part II: Implementation and tests in dune. Computing 82(2-3), 121-138 (2008b)

Becker, B., Beck, M., Fetzer, T., Flemisch, B., Grüninger, C., Hommel, J., Jambhekar, V., Kissinger, A., Koch, T., Schneider, M., Schröder, N., Schwenck, N.: Dumux 2.7.0. doi:10.5281/zenodo.16722 (2015)

Class, H., Helmig, R., Bastian, P.: Numerical simulation of non-isothermal multiphase multicomponent processes in porous media.: 1. an efficient solution technique. Adv. Water Resour. 25(5), 533-550 (2002)

Closmann, P.: Steam zone growth in a preheated reservoir. Soc. Pet. Eng. J. (United States) 8, 3 (1968)

Coats, K.: Reservoir simulation: A general model formulation and associated physical/numerical sources of instability (1980)

Coats, K., George, W., Chu, C., Marcum, B., et al.: Three-dimensional simulation of steamflooding. Soc. Petrol. Eng. J. 14(06), 573-592 (1974)

Coats, K., et al.: Simulation of steamflooding with distillation and solution gas. Soc. Petrol. Eng. J. 16(05), 235-247 (1976)

Falta, R.W., Pruess, K., Javandel, I., Witherspoon, P.A.: Numerical modeling of steam injection for the removal of nonaqueous phase liquids from the subsurface: 1. numerical formulation. Water Resour. Res. 28(2), 433-449 (1992a)

Falta, R.W., Pruess, K., Javandel, I., Witherspoon, P.A.: Numerical modeling of steam injection for the removal of nonaqueous phase liquids from the subsurface: 2 . code validation and application. Water Resour. Res. 28(2), 451-465 (1992b)

Flemisch, B., Darcis, M., Erbertseder, K., Faigle, B., Lauser, A., Mosthaf, K., Müthing, S., Nuske, P., Tatomir, A., Wolff, M., et al.: Dumu x: Dune for multi-phase, component, scale, physics, flow and transport in porous media. Adv. Water Resour. 34(9), 1102-1112 (2011)

Forsyth, P.A.: A positivity preserving method for simulation of steam injection for napl site remediation. Adv. Water Resour. 16(6), 351-370 (1993)

Ganapathy, V.: Understand steam generator performance. Chem. Eng. Prog.; (United States) 90(12) (1994)

German Federal Ministry for Economic Affairs and Energy (2014) Gesamtausgabe der Energiedaten - Datensammlung des BMWi. http://www.bmwi.de/BMWi/Redaktion/Binaer/energie-daten-gesamt,property= blob, bereich $=$ bmwi2012, sprache $=$ de, $r w b=$ true.$x l s$

Glandt, C., Vinegar, H., Prats, M.: Method of producing tar sand deposits containing conductive layers. http:// www.google.com/patents/US4926941, US Patent 4,926,941 (1990)

Gudbjerg, J.: Tr̈otschler, O., Färber, A., Sonnenborg, T., Jensen, K.: On spurious water flow during numerical simulation of steam injection into water-saturated soil. J. Contam. Hydrol. 75(34), 297-318 (2004)

Gudbjerg, J., Heron, T., Sonnenborg, T.O., Jensen, K.H.: Three-dimensional numerical modeling of steam override observed at a full-scale remediation of an unconfined aquifer. Groundw. Monit. Remediat. 25(3), 116-127 (2005)

Helmig, R.: Multiphase Flow and Transport Processes in the Subsurface. Springer, Berlin (1997)

Hiester, U., Müller, M., Koschitzky, H.P., Trötschler, O., Roland, U., Holzer, F.: Guidelines In situ thermal treatment (ISTT) for source zone remediation of soil and groundwater (2013)

Huber, R., Helmig, R.: Node-centered finite volume discretizations for the numerical simulation of multiphase flow in heterogeneous porous media. Computat. Geosci. 4, 141-164 (2000)

Looney, B., Falta, R.: Vadose Zone. Battelle Press, Columbus, OH (2000)

Luckner, L., Van Genuchten, M.T., Nielsen, D.: A consistent set of parametric models for the two-phase flow of immiscible fluids in the subsurface. Water Resour. Res. 25(10), 2187-2193 (1989)

Ochs, S.O., Hodges, R.A., Falta, R.W., Kmetz, T.F., Kupar, J.J., Brown, N.N., Parkinson, D.L.: Predicted heating patterns during steam flooding of coastal plain sediments at the savannah river site. Environ. Eng. Geosci. 9(1), 51-69 (2003)

Ochs, S.O., Class, H., Färber, A., Helmig, R.: Methods for predicting the spreading of steam below the water table during subsurface remediation. Water Resour. Res. 46(5), 1-16 (2010)

Somerton, W., El-Shaarani, A., Mobarak, S.: High temperature behavior of rocks associated with geothermal type reservoirs. 44th Annual California Regional Meeting of the Society of Petroleum Engineers, SPE, San Fransisco, CA., pp Paper SPE-4897 (1974)

van Genuchten, M.: A closed-form equation for predicting the hydraulic conductivity of unsaturated soils. Soil Sci. Soc. Am. J. 44, 892-898 (1980)

Van Lookeren, J., et al.: Calculation methods for linear and radial steam flow in oil reservoirs. SPE 6788, 9-12 (1983) 